$\stackrel{N / N}{=}$

Global burnals Inc.

(2)
GLOBAL JOURNAL OF MEDICAL RESEARCH: H

ORTHOPEDIC AND MUSCULOSKELETAL SYSTEM

Volume 21 Issue 2 Version 1.0 Year 2021

Type: Double Blind Peer Reviewed International Research Journal

Publisher: Global Journals Inc. (USA)

Online ISSN: 2249-4618 \& Print ISSN: 0975-5888

\title{
Are Prophylactic Antibiotics Necessary in Primarily Closed Lacerated Wounds?
}

\author{
By Dr. Faheem Quraishi, Dr. Iram Quraishi, Dr. A.G. Quraishi \\ \& Dr. Kashif Momin
}

Abstract- Objective: The objective of present study was to find if antibiotics really benefit in preventing infection in lacerations anywhere in body, provided copious irrigation \& meticulous surgical debridement is performed. Also, when wounds are contaminated. The study also took into consideration effect of length \& depth of wound on wound infection.

Methods: This longitudinal study was performed between November 2016 to June 2021 at Orthocare accident hospital \& research center, India. Patients were allocated in two groups. Patients in Group $A(n=221)$ were those who have received oral Amoxicillin \& Clavulanic acid for 7 days as per standard protocol ${ }^{21}$ and Group $B(n=189)$ patients did not receive antibiotics as per protocol in previous studies ${ }^{17}$. infection rate was measured in both group \& measured outcome was analyzed with SPSS version 20, IBM. Categorical data was presented as percentages and analyzed with Chi square or Fisher Exact test.

Keywords: wound infection, antibiotic prophylaxis, lacerated wounds, contaminated wounds, wound length, wound debridement, copious irrigation.

GJMR-H Classification: NLMC Code: WE 168

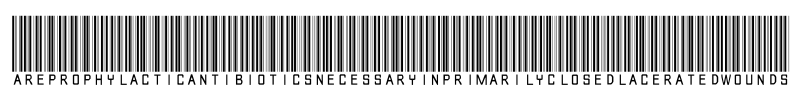

Strictly as per the compliance and regulations of:

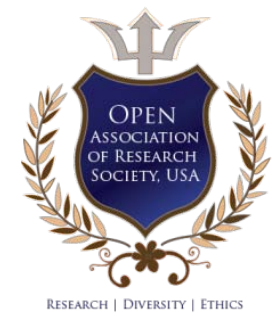

(C) 2021. Dr. Faheem Quraishi, Dr. Iram Quraishi, Dr. A.G. Quraishi \& Dr. Kashif Momin. This research/review article is distributed under the terms of the Attribution-NonCommercial-NoDerivatives 4.0 International (CC BY-NC-ND 4.0). You must give appropriate credit to authors and reference this article if parts of the article are reproduced in any manner. Applicable licensing terms are at https://creativecommons.org/licenses/by-nc-nd/4.0/. 


\title{
Are Prophylactic Antibiotics Necessary in Primarily Closed Lacerated Wounds?
}

\author{
Dr. Faheem Quraishi ${ }^{\alpha}$, Dr. Iram Quraishi ${ }^{\sigma}$, Dr. A.G. Quraishi ${ }^{\rho}$ \& Dr. Kashif Momin ${ }^{\omega}$
}

Abstract- Objective: The objective of present study was to find if antibiotics really benefit in preventing infection in lacerations anywhere in body, provided copious irrigation \& meticulous surgical debridement is performed. Also, when wounds are contaminated. The study also took into consideration effect of length \& depth of wound on wound infection.

Methods: This longitudinal study was performed between November 2016 to June 2021 at Orthocare accident hospital \& research center, India. Patients were allocated in two groups. Patients in Group $A(n=221)$ were those who have received oral Amoxicillin \& Clavulanic acid for 7 days as per standard protocol $^{21}$ and Group B $(n=189)$ patients did not receive antibiotics as per protocol in previous studies ${ }^{17}$. infection rate was measured in both group \& measured outcome was analyzed with SPSS version 20, IBM. Categorical data was presented as percentages and analyzed with Chi square or Fisher Exact test. Quantitative data was presented as Mean \& Median, range wherever applicable, and analyzed using student's t test or Mann Whitney U test.

Results: We found no significant difference in infection rate between Group A (2 out of 221) \& group B (1 out of 189 patients), $\mathrm{p}<0.05$.

Conclusion: This study shows that prophylactic antibiotic doesn't prevent infection in lacerated wounds sutured primarily, even if wounds are contaminated. Copious irrigation $\&$ meticulous debridement remain more crucial than antibiotics in preventing wound infection. Wound length \& depth also doesn't correlate with wound infection.

Keywords: wound infection, antibiotic prophylaxis, lacerated wounds, contaminated wounds, wound length, wound debridement, copious irrigation.

\section{INTRODUCTION}

T raumatic Lacerated wounds are routinely managed in emergency department on day care basis. The main aim of the treating surgeon is to achieve aesthetic \& fast healing of wounds. Wound infection remains a major threat not only to this outcome but also adds significant morbidity. It has been prevented for ages by copious irrigation, good wound debridement and antibiotic administration ${ }^{1}$.

Corresponding Author a: Orthocare Accident Hospital \& Research Centre, Manmad. Maharashtra state. India 423104.

e-mails: quraishifaheem@gmail.com,orthosurgeon01@gmail.com
Wound irrigation washes out debris \& dilutes bacterial load. Irrigation has no proven effect on wound healing \& infection but most of the studies support it. Instead, several RCT's prefer tap water over sterile saline for irrigation ${ }^{213,4,5,6}$. Wheeler et al recommended 50 to $100 \mathrm{ml}$ of irrigation solution per centimeter of wound to bring bacterial load below acceptable $10^{5}$ organism per $\mathrm{ml}^{7}$. Also use of clean non sterile gloves instead of sterile gloves has hardly found to have any effect on wound infection ${ }^{8}$.

Surgical debridement should aim at removal of debris and contaminants and excision of dead tissues. Debridement should be done in moderation. It should serve its very purpose but also should not devitalize skin and hamper functionality.

By and large, antibiotics take the maximum attention of treating surgeon. Though, Antibiotic prophylaxis guidelines exist depending on the contamination of wound, mechanism of injury, infection potential \& host predisposition ${ }^{9}$. There is a tendency to prescribe antibiotics fearing infection in almost all types of lacerated wounds. This overt use of antibiotics gives rise to bacterial resistance $\&$ adds to the cost of patient 1.In presence of contradictory studies, how far prophylactic antibiotics really benefit in lacerated wounds is unclear ${ }^{10,1112}$.

Many studies evaluated role of prophylactic antibiotics in preventing surgical site infection. But very few evaluated use of prophylactic antibiotic in preventing wound infection after suturing of simple contaminated lacerations ${ }^{13,14,15,16}$. In 1997 Cassell et al concluded that antibiotics were unnecessary for sharp upper limb lacerations, provided good surgical debridement is done ${ }^{17}$. Taking his observation further, the objective of present study was to find if antibiotics really benefit in preventing infection in lacerations anywhere in body, provided copious irrigation \& meticulous surgical debridement is performed. Also, when wounds are contaminated.

\section{Material \& Methods}

a) Study

This was a longitudinal study to compare outcomes of two groups of patients with lacerated wound sutured primarily treated with \& without prophylactic antibiotic. This study was performed between November 2016 to June 2021 at Orthocare 
accident hospital \& research center located in Manmad, India.

\section{b) Patients}

Patients attending emergency department lacerated wounds were registered for the study after obtaining their informed consent. Patients were allocated in two groups. Patients in Group A were those who have received oral Amoxicillin \& Clavulanic acid for 7 days as per standard protocol ${ }^{21}$ and Group B patients did not receive antibiotics as per previous studies. ${ }^{17}$

\section{c) Inclusion criteria}

All Patients with lacerated wounds presenting within 6 hours of injury that needed primary closure located anywhere in the body were included in the study. All types of simple \& contaminated wounds except gunshot wounds were included. These wounds included superficial and deep wounds exposing muscles, tendons and bones.

\section{d) Exclusion criteria}

All patients with co-morbities like Diabetes, Hypothyroidism, Renal or Hepatic disorders, Cancer, Rheumatoid arthritis and on steroids or DMARD's were excluded from study. Patients presenting more than 6 hours after injury and patients with grossly contaminated wounds where contaminants were embedded in soft tissues \& couldn't be debrided thoroughly were also excluded. Also sewage contaminated wounds were excluded. Wounds extending to joints, having underlying fracture, nerve or vascular injury were also excluded. Patient who did suture removal at other hospitals were also excluded from study.

\section{e) Treatment protocol}

All patients were treated at presentation in Minor Operation Theatre in Emergency Department. No prophylactic antibiotic before suturing was given \& all wounds were anesthetized with $1 \%$ Xylocaine local infiltration. All wounds were irrigated with normal saline. Wounds less than $5 \mathrm{~cm}$ were irrigated with $100 \mathrm{ml}$ \& wounds more than $5 \mathrm{~cm}$ were irrigated with $500 \mathrm{ml}$ of normal saline respectively. No Povidine iodine solution, Hydrogen peroxide, Spirit or other antiseptic solution were used for wound wash or in wound preparation. Wound closure was done using sterile gloves \& drapped with sterile hole sheets. Skin closure was done with Nylon \& Vicryl was used for subcutaneous closure if required. Dressings were done with sterile gauzes \& povidone iodine ointment. Wound dressings were done on day 3 and 7 provided blood soakage was not there. Patients were cautioned against signs of infection like erythema, fever, purulent discharge, foul smell, sudden increase in pain \& were advised to report to hospital immediately. Facial wound sutures were removed between day 5-7, elsewhere in body suture removal was done between 10-14 days. In case if infection ensued in Group A (patients on prophylactic oral Amoxycillin \&
Clavulanic acid) oral Linezolid was given for 7 days. Whereas, if infection occurred in Group B (patients not on any prophylactic antibiotic) oral Amoxicillin \& Clavulanic acid were given for 7 days.

\section{f) Data Collection \& Statistical analysis}

Suturing \& Group allotment was done by orthopedic surgeon of the hospital. Suture removal was done by maxillofacial surgeon \& medical officer of hospital. Outcomes were recorded by maxillofacial surgeon of hospital. Data was recorded in excel sheet \& outcome was analyzed with SPSS version 20, IBM. Categorical data was presented as percentages and analyzed with Chi square or Fisher Exact test. Quantitative data was presented as Mean \& Median, range wherever applicable, and analyzed using student's t test or Mann Whitney U test.

\section{RESUlTS}

During the study duration 653 patients were treated for lacerated wounds.410 Patients were included in study, of which 308 were male \& 102 were female.221 patients received antibiotics\& were included in group A. 189 didn't receive antibiotics in any form hence were included in group B. The average age of patient in group A was 29.10 years with a range 1.5 to 90 years \& in group B average age was 29.13 years with a range 2 to 81 years (Table 1 ).

Since our study included lacerations all around body 81(group A 44, group B 37) lacerated wounds were located on upper limbs, 105 (group A 57, group B 48) on lower limbs, 221 (group A 119, group $B$ 102) on head \& neck \& 3 (group A 1 , group B 2) on trunk. The average length of wound was $5.1 \mathrm{~cm}$ (group A $5.5 \mathrm{~cm}$, group $B 4.7 \mathrm{~cm}$ ) with a range of 1.5 to $26 \mathrm{~cm}$ (group A $1.5 \mathrm{~cm}$ to $26 \mathrm{~cm}$, group B $1.5 \mathrm{~cm}$ to $18 \mathrm{~cm}$ ). (Table 2 )

Total 2 patients from group A developed infection \& 1 patient from group $B$ developed infection (Table 3). Out of these, one infected patient of Group A was a 63 years old female who had sustained wound over anterior aspect of left knee measuring $10 \mathrm{~cm}$ after Road traffic accident. $2^{\text {nd }}$ infected patient from Group A was 35 years old male who sustained $7 \mathrm{~cm}$ laceration over left palmar aspect of hand from dough machine. Both patients were put on oral Linezolid \& wound debridement was done. It took 4 weeks for complete healing of wounds. Single patient infected of Group B was a 21 years old male with $6 \mathrm{~cm}$ laceration over dorsal foot. This patient was put on oral Amoxycillin \& Clavulanic acid \& wound debridement was done. Wound healed in 24 days completely. All infected wounds healed with no disability except scarring. (Table 4)

We found no significant difference in infection rate between Group A (2 out of 221) \& group B (1 out of 189 patients), $p<0.05$ (Table 3). 
Table 1: Gender \& Age distribution of patients

\begin{tabular}{|c|c|c|c|}
\hline Category & $\begin{array}{c}\text { Male } \\
\text { No (\%) }\end{array}$ & $\begin{array}{c}\text { Female } \\
\text { No }(\%)\end{array}$ & Age range \& Median \\
\hline Group A & $165(74.66)$ & $56(25.34)$ & 1.5 to 90 years(32 years) \\
\hline Group B & $143(75.66)$ & $46(24.34)$ & 2 to 81 years(38 years) \\
\hline Total & $308(75.16)$ & $102(24.84)$ & 1.5 to 90 years(35 years) \\
\hline
\end{tabular}

Table 2: Anatomical distribution \& length of wounds

\begin{tabular}{|c|c|c|c|c|c|}
\hline Category & $\begin{array}{c}\text { Upper limb } \\
\text { No (\%) }\end{array}$ & $\begin{array}{c}\text { Lower limb } \\
\text { No (\%) }\end{array}$ & $\begin{array}{c}\text { Head \& neck } \\
\text { No (\%) }\end{array}$ & $\begin{array}{c}\text { Trunk } \\
\text { No (\%) }\end{array}$ & $\begin{array}{c}\text { Range \& Mean } \\
\text { Length }\end{array}$ \\
\hline Group A & $44(19.90)$ & $57(25.79)$ & $119(53.85)$ & $1(0.46)$ & $\begin{array}{c}1.5 \text { to } 26 \mathrm{~cm} \\
\text { (5.5cm) }\end{array}$ \\
\hline Group B & $37(19.6)$ & $48(25.40)$ & $102(54)$ & $2(1)$ & $\begin{array}{c}1.5 \text { to } 18 \mathrm{~cm} \\
(4.7 \mathrm{~cm})\end{array}$ \\
\hline Total & $81(19.76)$ & $105(25.61)$ & $221(53.9)$ & $3(0.73)$ & $\begin{array}{c}1.5 \text { to } 26 \mathrm{~cm} \\
(5.1 \mathrm{~cm})\end{array}$ \\
\hline
\end{tabular}

Table 3: Infection rate in patients

\begin{tabular}{|c|c|c|}
\hline Category & $\begin{array}{c}\text { Infected } \\
\text { No (\%) }\end{array}$ & $\begin{array}{c}\text { Un-infected } \\
\text { No (\%) }\end{array}$ \\
\hline Group A & $2(0.9)$ & $219(99.1)$ \\
\hline Group B & $1(0.5)$ & $188(99.5)$ \\
\hline Total & $3(0.73)$ & $407(99.27)$ \\
\hline
\end{tabular}

Fisher Exact Test, $p=1$. The result was not significant, $p<0.05$

Table 4: Details of infected patients

\begin{tabular}{|c|c|c|c|c|c|c|c|}
\hline Patient & $\begin{array}{c}\text { Group } \\
\text { allotted }\end{array}$ & Age & Sex & Mode of injury & Location & $\begin{array}{c}\text { Length } \\
\text { (cm) }\end{array}$ & \begin{tabular}{c} 
Final outcome \\
\hline 1.
\end{tabular} \\
A & 63 & female & Road traffic accident & Knee & 10 & $\begin{array}{c}\text { Healed with } \\
\text { scarring }\end{array}$ \\
\hline 2. & A & 35 & Male & Dough machine & Hand & 7 & $\begin{array}{c}\text { Healed with } \\
\text { scarring }\end{array}$ \\
\hline 3. & B & 21 & Male & Road traffic accident & Foot & 6 & $\begin{array}{c}\text { Healed with } \\
\text { scarring }\end{array}$ \\
\hline
\end{tabular}

\section{Discussion}

With the proven usefulness of prophylactic antibiotic in preventing surgical site infection, a general consensus started to grow that prophylactic antibiotic have same effect in preventing infection in sutured lacerated wounds. Eventually the focus of treating surgeon started shifting from essential measures like debridement \& wound irrigation to antibiotics. It was followed by overt antibiotic usage for sutured wound \& still higher antibiotics for various surgical procedures. Then studies started evaluating usefulness of one prophylactic antibiotic over the other. With passing years antibiotics usage completely overshadowed the basic principles of preventing wound infection in sutured wounds.

The intention of the study was to allay apprehension of treating surgeon about wound infection and to bring into notice real measures effective in preventing wound infection. This study evaluated whether prophylactic antibiotic usage was prudent for preventing infection in primarily closed lacerated wounds. It also emphasized how effective debridement $\&$ wound irrigation are in preventing infection.

The study showed in spite of giving antibiotics in effective doses there was no clinically significant benefit of prophylactic antibiotic in lacerated wounds, even contaminated wounds. This was also supported by multiple studies \& meta analysis ${ }^{18,19,20}$. In fact, there are added problems with overt antibiotic usage. It adds to development of bacterial resistance, chances of developing allergic reaction \& adds to the financial burden of patient. ${ }^{21,22,23,24}$. Antibiotic usage must be tailored as per degree of bacterial contamination, type of contaminants like sewage water \& host vulnerability factors for infection.

Wound debridement is most essential in preventing wound infection, it removes all dead tissues that act as a good medium for bacterial growth ${ }^{25,26}$, so was emphasized in current study. All wounds were thoroughly debrided by qualified \& experienced surgeons. Probably this crucial factor helped preventing wound infection in all the wounds in this study also. Wound irrigation is also effective in preventing infection. It dilutes the bacterial load of wound \& washes out 
debris, clots \& contaminants. It should always be accompanied by good debridement to get optimum results.

Another consensus has been longer the wounds more chances of infection. W.H.O. (World Health Organisation) also recommends antibiotic prophylaxis for wounds longer than $5 \mathrm{~cm}$ considering increased chances of infections ${ }^{27}$. Though, in current study all infected wounds were greater than $5 \mathrm{~cm}$. The correlation between wound length \& infection didn't prove significant as many lacerations longer than the infected ones healed uneventfully. Also wound depth didn't affect the outcome. No correlation was found between wound depth \& incidence of infection.

Holistically, prophylactic antibiotic usage doesn't allow treating surgeon overlook good wound debridement \& irrigation. Infact prophylactic antibiotic usage has no bearing in preventing wound infection if good debridement \& copious irrigation is done. Length \& depth of wound also appears not to affect incidence of wound infection.

\section{Conclusion}

This study shows that prophylactic antibiotic doesn't prevent infection in lacerated wounds sutured primarily, even if wounds are contaminated. Copious irrigation \& meticulous debridement remain more crucial than antibiotics in preventing wound infection. Wound length \& depth also doesn't correlate with wound infection.

Hence, treating surgeon should concentrate on copious irrigation \& meticulous debridement rather than relying on prophylactic antibiotics for preventing wound infection.

\section{ACKNOWLEDGEMENT}

Authors wish to express gratitude towards entire hospital staff of Orthocare Accident Hospital \& Research Centre, Manmad for contributing to this study by helping in data collection \& record keeping.

Conflict of interest

Authors express no conflict of interest.

\footnotetext{
${ }^{1}$ Hameed Basir Ghafouri, Barzin Bagheri Behzad, Mohammed Reza Yasinzadeh; Prophylactic antibiotic therapy in contaminated traumatic wounds: two days versus five days treatment.

${ }^{2}$ Worster B, Zawora MQ, Hsieh C. Common questions about wound care. Am Fam Physician. 2015; 91(2): 86-92.

3 Fernandez R, Griffiths R. Water for wound cleansing. Cochrane Database Syst Rev. 2012; (2): CD003861

${ }^{4}$ Xia Y, Cho S, Greenway HT, Zelac DE, Kelley B. Infection rates of wound repairs during Mohs micrographic surgery using sterile versus nonsterile gloves: a prospective randomized pilot study. Dermatol Surg. 2011; 37(5): 651-656.
}

${ }^{5}$ Moscati RM, Mayrose J, Reardon RF, Janicke DM, Jehle DV. A multicenter comparison of tap water versus sterile saline for wound irrigation. Academic Emergency Med. 2007; 14(5): 404-409.

${ }^{6}$ Weiss EA, Oldham G, Lin M, Foster T, Quinn JV. Water is a safe and effective alternative to sterile normal saline for wound irrigation prior to suturing: a prospective, double-blind, randomised, controlled clinical trial. BMJ Open. 2013; 3(1).

7 Wheeler CB, Rodeheaver GT, Thacker JG, Edgerton MT, Edilich RF. Side-effects of high pressure irrigation. Surg Gynecol Obstet. 1976; 143(5): 775-778

8 Randall T.Forsch, Sahoko H.Little, Christa Williams Laceration repair: Apractical Approach; University of Michigan Medical School, AnnArbor, Michigan.

9 Singer AJ, Hollander JE, Quinn JV. Evaluation and management of traumatic lacerations. N Engl J Med 1997; 337: $1142-8$

10 Cummings $\mathrm{P}$, Del Beccaro MA. Antibiotics to prevent infection of simple wounds: a meta analysis of randomized studies. Am J Emerg Med 1995; 13: 396-400

${ }^{11}$ Zehtabchi S. Evidence-based emergency medicine/ critically appraised topic. The role of antibiotic prophylaxis for prevention of infection in patients with simple hand lacerations. Ann Emerg Med 2007; 49: 682-9, 689. 4. Cowell DL, Harvey M, Cave G. Antibiotic prophylaxis at triage for simple traumatic wounds: a pilot study. Eur J Emerg Med 2011; 18: 279-81.

12 Cowell DL, Harvey M, Cave G. Antibiotic prophylaxis at triage for simple traumatic wounds: a pilot study. Eur J Emerg Med 2011; 18: 279-81.

${ }^{13}$ Rodgers KG. 1992. The rational use of antimicrobial agents in simple wounds. Emerg Med Clin North Am, 10, 753-756.

${ }^{14}$ Sacks T. 1988. Prophylactic antibiotics in traumatic wounds. J Hosp Inf, 11, (Suppl. A), 251-258.

15 Berk WA, Welch RD and Bock BF. 1992. Controversial issues in clinical management of the simple wound. Ann Emerg Med, 21, 72-80.

16 Trott AT. 1991. Wounds and Lacerations: Emergency Care and Closure. St. Louis, Mo, Mosby-Year Book.

17 O.C.S. Cassell and I.Ion; Are antibiotics necessary in the surgical management of upper limb lacerations? British journal of Plastic Surgery..Trott AT. 1991. Wounds and Lacerations: Emergency Care and Closure. St. Louis, Mo, Mosby-Year Book.

${ }^{18}$ Cummings $P$ and Del Beccaro MA. 1995. Antibiotics to prevent infection of simple wounds: a meta-analysis of randomized studies. Am J Emerg Med, 13, 396-400.

19 Roberts A and Teddy P. 1977. A prospective trial of prophylac-tic antibiotics in hand lacerations. Br J Surg, 64, 394-396.

20 Thirlby RC, Blair AJ and Thal ER. 1983. The value of prophylactic antibiotics for simple lacerations. Surg Gynecol Obstet, 156, 212-216.

${ }^{21}$ Stone S and Carter WA. 2004. Wound preparation, In: Emergency Medicine a comprehensive study guide. Tintinalli JE, Kelen GD and Stapcynski JS (eds.), New York, McGraw Hill, pp 289-291.

22 Perelman VS, Francis GJ, Rutledge T, Foote J, Martino F and Dranitsaris G. 2004. Sterile Versus Nonsterile Gloves for Re-pair of Uncomplicated Lacerations in the Emergency Department: A Randomized Controlled Trial. Ann Emerg Med, 43, 362-370. 
${ }^{23}$ Hoth JJ, Franklin GA, Stassen NA, Girard SM, Rodriguez RJ and Rodriguez JL. 2003. Prophylactic Antibiotics Adversely Affect Nosocomial Pneumonia in Trauma Patients. J Trauma, 55, 249-254.

${ }^{24}$ Terpstra S, Noordhoek GT, Voesten HG Hendriks B and Degener JE. 1999. Rapid emergence of resistant coagulase nega-tive staphylococci in the skin after antibiotic prophylaxis. J Hosp Infect, 43, 195-202.

${ }^{25}$ Peacock K, Hanna D, Kirkpatrick K, Breidenbach W, Lister G, Firrell J. Efficacy of perioperative cefamandole with postoperative cephalexin in the primary outpatient treatment of open wounds of the hand. J Hand Surg (Am) 1988; 13: 9604.

${ }^{26}$ Ham-y B, Rodeheaver G, Vensko J, Edgerton MT, Edlich RF. Debridement: An essential component of traumatic wound care. Am J Surg 1978; 135: 23842.

${ }^{27}$ Prevention \& management of wound infection; Department of violence \& injury prevention \& disability World Health Organization. 